\title{
Effect of daphnoretin on the proliferation and apoptosis of A549 lung cancer cells in vitro
}

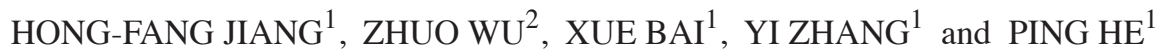 \\ ${ }^{1}$ Department of Geriatrics, Shengjing Hospital of China Medical University, ${ }^{2}$ Department of Thoracic Surgery, \\ The Fourth Affiliated Hospital of China Medical University, Shenyang, Liaoning 110004, P.R. China
}

Received October 29, 2013; Accepted May 23, 2014

DOI: $10.3892 / \mathrm{ol} .2014 .2296$

\begin{abstract}
Daphnoretin is an active constituent of Wikstroemia indica C.A. Mey., which is widely distributed in the northwest and southwest regions of China. Previous studies have shown that daphnoretin has anticancer effects on leukemia, osteosarcoma and uterine cervix cancer cells. However, the effect of daphnoretin on human lung cancer cells has yet to be elucidated. In the present study, daphnoretin was observed to inhibit A549 lung cancer cell proliferation in a concentrationand time-dependent manner. Fluorescent microscopy and flow cytometric analysis showed that daphnoretin induced A549 cell apoptosis in a concentration-dependent manner. Western blot analysis also revealed that daphnoretin induced apoptosis through the regulation of the B-cell lymphoma-2 gene family in A549 cells. These findings indicate that daphnoretin may have potential as a therapeutic agent for the management of lung cancer.
\end{abstract}

\section{Introduction}

Lung cancer is one of the most frequently diagnosed types of cancer and the leading cause of cancer-associated mortality worldwide (1). Despite the development and use of multimodality therapies, including surgery, radiotherapy, conventional chemotherapy and molecular targeted therapy, the clinical outcome of lung cancer treatment remains unsatisfactory, with a five-year overall survival rate of $<15 \%$ (2). This may be, at least in part, due to the side-effects associated with currently available chemotherapeutic drugs and the resistance of advanced lung cancer (3). Therefore, novel, effective chemotherapeutic agents are required, particularly those that are derived from natural products due to their intrinsic advantages (4-6).

Correspondence to: Dr Ping He, Department of Geriatrics, Shengjing Hospital of China Medical University, 36 Sanhao Road, Shenyang, Liaoning 110004, P.R. China

E-mail: cmu-sj@hotmail.com

Key words: daphnoretin, A549 lung cancer cell, natural compound, apoptosis
Daphnoretin (Fig. 1) is an active constituent of Wikstroemia indica C.A. Mey. which belongs to the Thymelaceae family and is widely distributed throughout the northwest and southwest regions of China. The root of this plant is used as a remedy for arthritis, tuberculosis, syphilis and pertussis (7). Previous studies have shown that daphnoretin has a number of biological activities, including antifungal effects (8), as well as the inhibition of various sites involved in DNA synthesis (9), the activation of protein kinase $C$ in platelet aggregation $(7,10)$, an antiviral effect on hepatitis B (11) and respiratory syncytial virus properties (12). Furthermore, the anticancer effect of daphnoretin has been reported in various studies (13-15). Such studies have shown that daphnoretin exerts its anticancer effects through the inhibition of cancer cell proliferation, the induction of $\mathrm{G}_{2} / \mathrm{M}$-phase arrest and apoptosis. However, the effect of daphnoretin on human lung cancer cells has yet to be elucidated.

The present study aimed to investigate the effect of daphnoretin on the growth of A549 lung cancer cells and the cellular mechanism involved in daphnoretin-induced apoptosis. The findings of the present study suggest that daphnoretin may have potential as an anticancer agent for lung cancer therapy.

\section{Materials and methods}

Reagents and chemicals. Daphnoretin was purchased from the National Institute for the Control of Pharmaceutical and Biological Products (Beijing, China) and a 1-mmol/1 stock solution of daphnoretin was prepared in dimethyl sulfoxide (DMSO) and stored at $-20^{\circ} \mathrm{C}$. Deionized water was used in all of the experiments. Fetal bovine serum(FBS) was purchased from Solarbio Science and Technology Co., Ltd. (Beijing, China), and 3-(4,5-Dimethylthiazol-2-yl)-2,5-diphenyltetrazolium bromide (MTT), Hoechst 33342 and DMSO were purchased from Sigma-Aldrich (St. Louis, MO, USA). An Annexin V-fluorescein isothiocyanate (FITC) and propidium iodide (PI) double-staining kit was purchased from KeyGene Inc. (Nanjing, China). Mouse monoclonal anti-human, anti-mouse and anti-rat antibodies against Bcl-2-associated $\mathrm{X}$ protein (Bax) (catalogue number, sc-23959), B-cell lymphoma (Bcl)-2 (catalogue number, sc-7382) and glyceraldehyde-3-phosphate dehydrogenase (GAPDH; catalogue number, sc-365062) were obtained from Santa Cruz Biotechnology, Inc. (Santa Cruz, CA, USA). The secondary 
polyclonal horseradish peroxidase-conjugated goat anti-mouse and anti-rabbit antibodies were also obtained from Santa Cruz Biotechnology, Inc. All other reagents were obtained from Sinopharm Chemical Reagent Co., Ltd. (Shenyang, China).

Cell culture. The A549 human lung cancer cell line was obtained from the China Center for Type Culture Collection (Wuhan, China) and maintained in RPMI-1640 supplemented with $10 \% \mathrm{FBS}, 100 \mathrm{U} / \mathrm{ml}$ penicillin and $100 \mu \mathrm{g} / \mathrm{ml}$ streptomycin at $37^{\circ} \mathrm{C}$ in a humidified atmosphere of $5 \% \mathrm{CO}_{2}$.

MTT assay. The effect of daphnoretin on the proliferation of A549 cells was measured using MTT assay. In brief, A549 cells were plated at a density of $1 \times 10^{4}$ cells per well on 96-well plates overnight, then treated with various concentrations of daphnoretin $(0,5,10,15$ and $20 \mu \mathrm{mol} / \mathrm{l})$ for 24 and $48 \mathrm{~h}$. A total of $20 \mu \mathrm{l}$ MTT solution [ $2 \mathrm{mg} / \mathrm{ml}$ in phosphate-buffered saline (PBS)] was added to each well and the cells were cultured for $4 \mathrm{~h}$ at $37^{\circ} \mathrm{C}$. The medium was then removed and $150 \mu \mathrm{l}$ DMSO was added to solubilize the MTT formazan crystals. The plates were then agitated and the optical density was determined at $570 \mathrm{~nm}$ using an ELISA plate reader (Model 550; Bio-Rad Laboratories, Inc., Hercules, CA, USA). At least three independent experiments were performed.

Fluorescence microscopy. A549 cells $\left(1 \times 10^{6}\right)$ were seeded on six-well plates overnight, then treated with different concentrations of daphnoretin $(0$ and $10 \mu \mathrm{mol} / \mathrm{l})$ for $24 \mathrm{~h}$. The cells were washed twice with cold PBS, fixed with cold methanol and acetic acid $(3 / 1, \mathrm{v} / \mathrm{v})$ for $30 \mathrm{~min}$ and then stained with Hoechst $33342(1 \mathrm{mg} / \mathrm{ml})$ for $30 \mathrm{~min}$ in the dark. The stained cells were observed using a fluorescence microscope (magnification, x400; Nikon E800; Nikon Corporation, Tokyo, Japan).

Flow cytometric analysis. The apoptotic rates of the A549 cells were determined using flow cytometric analysis using an Annexin V-FITC apoptosis kit. In brief, A549 cells $\left(1 \times 10^{6}\right)$ were seeded on six-well plates overnight, then treated with various concentrations of daphnoretin $(0,5,10$ and $15 \mu \mathrm{mol} / \mathrm{l})$ for $24 \mathrm{~h}$. Cells $\left(1 \times 10^{6}\right)$ were then harvested using centrifugation $(326 \mathrm{xg}$ ) for $5 \mathrm{~min}$ and washed twice with cold PBS. Staining was performed according to the manufacturer's instructions (KeyGene Inc.) and the cells were analyzed using a FACScan flow cytometer (Becton-Dickinson, San Jose, CA, USA). At least three independent experiments were performed.

Western blot analysis. The expression of apoptosis-related proteins was assessed using western blot analysis. In brief, A549 cells $\left(1 \times 10^{6}\right)$ were seeded on six-well plates overnight, then treated with various concentrations of daphnoretin $(0$, 5,10 and $15 \mu \mathrm{mol} / \mathrm{l}$ ). Following treatment for $24 \mathrm{~h}$, the total proteins were solubilized and extracted using lysis buffer (20 mM HEPES, pH 7.9, 20\% glycerol, $200 \mathrm{mM} \mathrm{KCl,} 0.5 \mathrm{mM}$ EDTA, $0.5 \%$ NP-40, $0.5 \mathrm{mM}$ dithiothreitol and $1 \%$ protease inhibitor cocktail). The protein concentration was determined using a bicinchoninic acid protein assay. All samples were separated using SDS-PAGE to determine the protein expression of Bax, Bcl-2 and GAPDH. Blots were developed using an enhanced chemiluminescence kit.

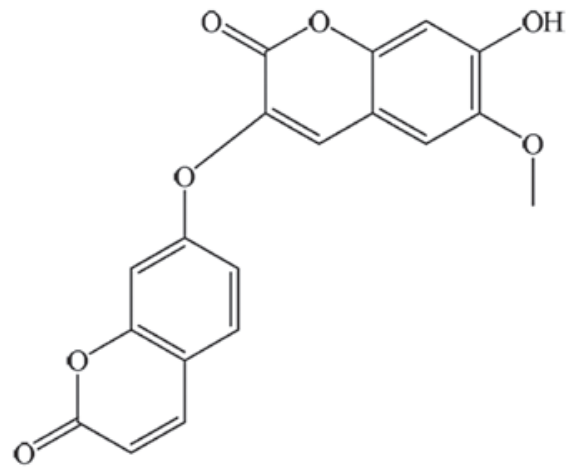

Figure 1. Structure of daphnoretin.

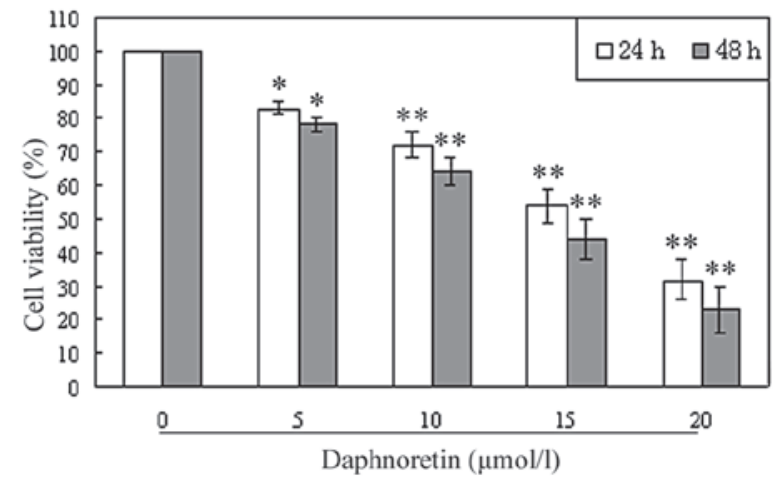

Figure 2. Proliferation-inhibiting effects of daphnoretin on A549 lung cancer cells. ${ }^{*} \mathrm{P}<0.05$ and ${ }^{* *} \mathrm{P}<0.01$, vs. the respective control group.

Statistical analysis. Statistical analyses were performed using the SPSS 13.0 package (SPSS, Inc., Chicago, IL, USA). All experiments were performed at least three times. All data are expressed as the mean \pm standard deviation. The statistical correlations of the data were tested for significance using analysis of variance and the Student's t-test. $P<0.05$ and $P<0.01$ were considered to indicate statistically significant differences.

\section{Results}

Daphnoretin inhibits A549 cell proliferation. To investigate the growth-inhibiting effect of daphnoretin, A549 cells were treated with various concentrations of A549 for 24 and $48 \mathrm{~h}$, and the rate of inhibition was determined using MTT assay. As shown in Fig. 2, A549 cell growth was observed to be inhibited in a concentration- and time-dependent manner.

Daphnoretin induces A549 cell apoptosis. To investigate the apoptosis-inducing effect of daphnoretin, A549 cells were treated with various concentrations of daphnoretin. Following treatment with daphnoretin $(0$ and $10 \mu \mathrm{mol} / \mathrm{l})$ for $24 \mathrm{~h}$, cells were analyzed using fluorescent microscopy with Hoechst 33324 staining. As shown in Fig. 3, chromatin condensation, nuclear fragmentation and apoptotic bodies were observed in the treated cells. The results revealed that when exposed to daphnoretin, A549 cells underwent the typical morphological changes that are associated with apoptosis.

The ratio of apoptotic cells induced by daphnoretin was measured using flow cytometry. A549 cells were treated with 


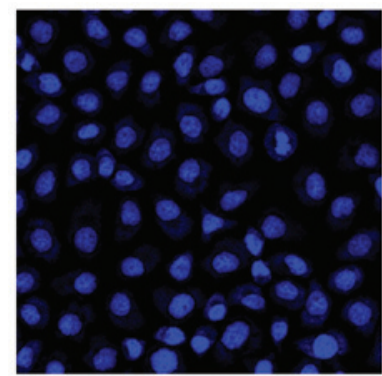

0

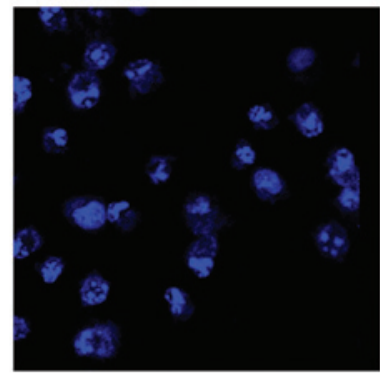

10

Daphnoretin $(\mu \mathrm{mol} / \mathrm{l})$

Figure 3. Cell apoptosis observed using Hoechst 33342 staining. A549 cells were treated with daphnoretin (0 or $10 \mu$ mol/1) for 24 h. The apoptotic cells exhibited chromatin condensation, nuclear fragmentation and apoptotic bodies.

A
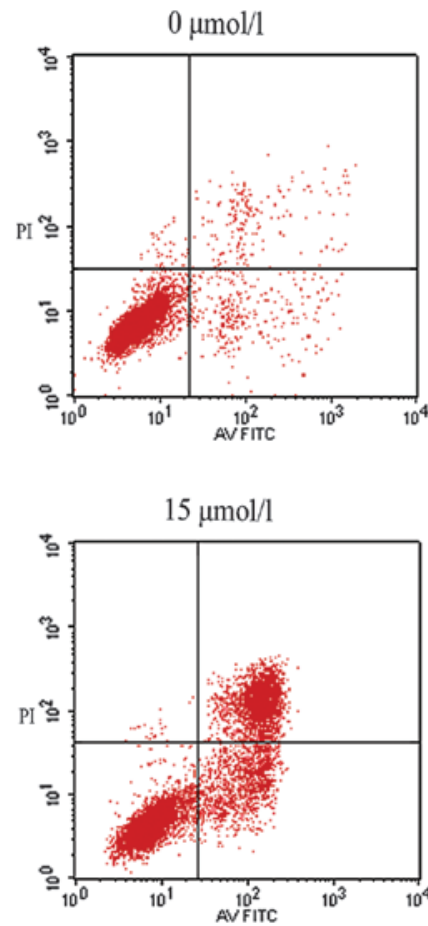
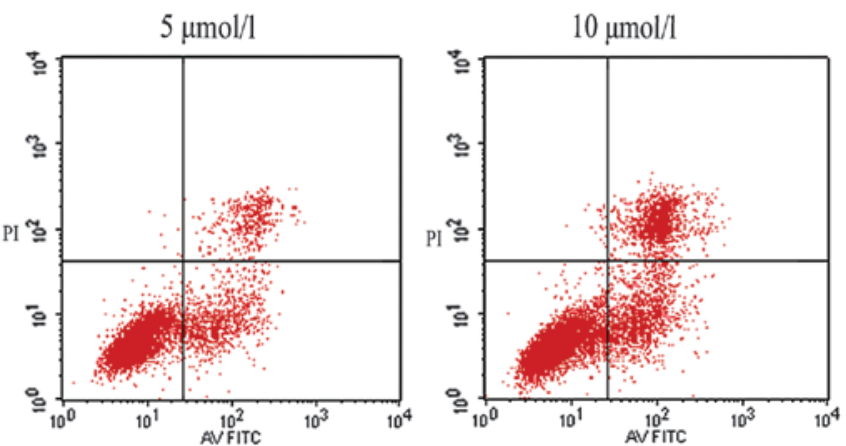

B

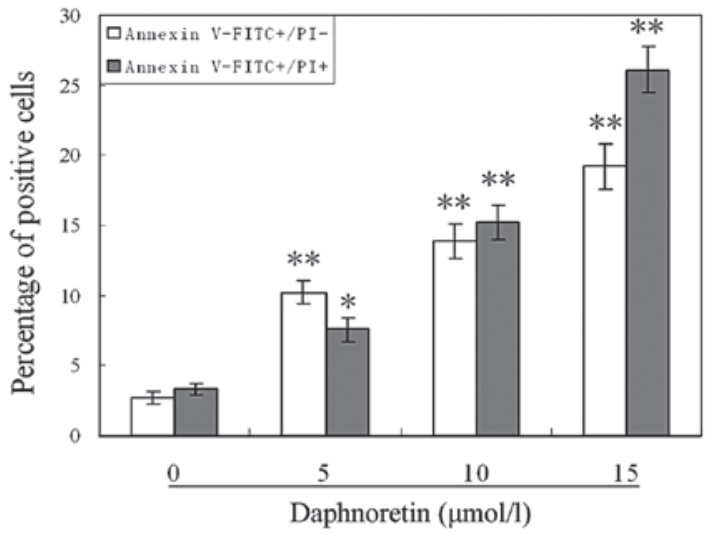

Figure 4. (A) Daphnoretin-induced apoptosis in A549 cells detected using flow cytometry. A549 cells were treated with daphnoretin $(0,5,10$ and $15 \mu$ mol/l) for $24 \mathrm{~h}$. The cells were then harvested and stained with Annexin V and PI and flow cytometric analysis was performed to analyze apoptosis. (B) Summary of the apoptosis data. ${ }^{*} \mathrm{P}<0.05$ and ${ }^{* *} \mathrm{P}<0.01$, vs. the respective control group. AV, avidin; FITC, fluorescein isothiocyanate; PI, Bpropidium iodide.

various concentrations of daphnoretin $(0,5,10$ and $15 \mu \mathrm{mol} / \mathrm{l})$ for $24 \mathrm{~h}$ and analyzed using flow cytometry with Annexin V and PI staining. As shown in Fig. 4, the ratio of early and late apoptotic cells was observed to be significantly increased in the daphnoretin-treated cells compared with the cells in the control group. The results show that when treated with daphnoretin for $24 \mathrm{~h}$, the ratio of apoptotic cells significantly increased in a concentration-dependent manner.

Effect of daphnoretin on Bcl-2 family gene expression. The expression of apoptosis-related proteins was assessed using western blot analysis. As shown in Fig. 5, daphnoretin treatment induced an increase in Bax protein expression and a reduction in $\mathrm{Bcl}-2$ protein expression compared with

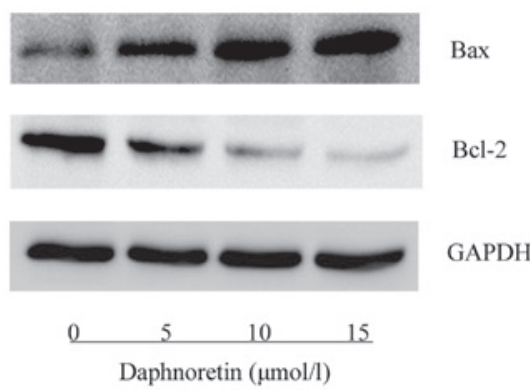

Figure 5. Effect of daphnoretin on Bcl-2 family protein expression detected using western blot analysis. A549 cells were treated with daphnoretin (0, 5,10 and $15 \mu \mathrm{mol} / \mathrm{l}$ ) for $24 \mathrm{~h}$. Proteins were then extracted and Bax, Bcl-2 and GAPDH expression were analyzed using western blot analysis. Bcl, B-cell lymphoma; Bax, Bcl-2-associated X protein; GAPDH, glyceraldehyde-3-phosphate dehydrogenase. 
the control cells. The ratio of Bax to Bcl-2 was observed to increase in a concentration-dependent manner.

\section{Discussion}

Increasing research attention has been focused on phytochemicals in the search for novel anticancer agents with enhanced efficacy to cancer cells and reduced toxicity to normal cells. Daphnoretin, isolated from Wikstroemia indica C.A. Mey. (16) as well as Daphne mezereum L. and Daphne cannabina Wall. (17), have been shown to induce cell cycle arrest and apoptosis in leukemia, osteosarcoma and HeLa cells (13-15). These findings suggest that daphnoretin may have potential as a novel anti-cancer agent.

In the present study, the results demonstrated that daphnoretin inhibited the growth of A549 lung cancer cells in a concentration- and time-dependent manner. A549 cells treated with daphnoretin exhibited typical apoptotic characteristics, including cytoplasmic shrinkage, plasma membrane blebbing, nuclear chromatin condensation, chromosomal DNA cleavage and fragmentation of the cells into membrane-enclosed vesicles or apoptotic bodies. Flow cytometric analysis revealed that daphnoretin induced A549 cell apoptosis in a concentration-dependent manner. Moreover, $\mathrm{Bax} / \mathrm{Bcl}-2$ were found to be involved in the molecular mechanism of daphnoretin-induced apoptosis in A549 cells.

Apoptosis is a type of programmed cell death which occurs through the activation of intrinsic cell suicide pathways (18). Apoptosis is a hallmark of anticancer drug-induced cell death (19). Proteins of the Bcl-2 family are key regulators of the apoptotic pathway $(20,21)$. The Bcl-2 gene family, which is significantly involved in the regulation of cell apoptosis, includes anti-apoptotic genes, including Bcl-2 and Bcl-extra large and pro-apoptotic genes including, Bax, $\mathrm{Bcl} 2$-antagonist/killer, Bcl-2-interacting killer, BH3 interacting-domain death agonist and $\mathrm{Bcl} 2$-associated agonist of cell death $(22,23)$. Certain traditional Chinese anticancer drugs have been found to induce cell apoptosis through targeting the proteins of the Bcl-2 family and the ratio of Bax/Bcl-2 $(24,25)$. In the present study, western blot analysis revealed that the daphnoretin-induced apoptosis in the A549 cells was mediated through the downregulation of $\mathrm{Bcl}-2$ protein expression and the upregulation of Bax protein expression.

In conclusion, the present study has demonstrated that daphnoretin is capable of inhibiting proliferation and promoting apoptosis in A549 lung cancer cells. Furthermore, this apoptotic response is associated with the regulation of the expression of the Bcl-2 gene family. These findings indicate that daphnoretin may have potential as a therapeutic agent for the management of lung cancer.

\section{Acknowledgements}

The present study was supported by the Outstanding Scientific Fund of Shengjing Hospital (grant no. 201205).

\section{References}

1. Bray F, Jemal A, Grey N,Ferlay J and Forman D: Global cancer transitions according to the Human Development Index (2008-2030): a population-based study. Lancet Oncol 13: 790-801, 2012.
2. Erridge SC, Møller H, Price A and Brewster D: International comparisons of survival from lung cancer: pitfalls and warnings. Nat Clin Pract Oncol 4: 570-577, 2007.

3. Li S, Bao P, Li Z, et al: Inhibition of proliferation and apoptosis induced by a Na$/ \mathrm{H}^{+}$exchanger- 1 (NHE-1) antisense gene on drug-resistant human small cell lung cancer cells. Oncol Rep 21: 1243-1249, 2009.

4. Hsu SC, Ou CC, Chuang TC, et al: Ganoderma tsugae extract inhibits expression of epidermal growth factor receptor and angiogenesis in human epidermoid carcinoma cells: In vitro and in vivo. Cancer Lett 281: 108-116, 2009.

5. Su CC and Lin YH: Tanshinone IIA down-regulates the protein expression of ErbB-2 and up-regulates TNF-alpha in colon cancer cells in vitro and in vivo. Int J Mol Med 22: 847-851, 2008.

6. Carter BZ, Mak DH, Schober WD, et al: Triptolide sensitizes AML cells to TRAIL-induced apoptosis via decrease of XIAP and p53-mediated increase of DR5. Blood 111: 3742-3750, 2008.

7. Ko FN, Chang YL, Kuo YH, Lin YL and Teng CM: Daphnoretin, a new protein kinase $\mathrm{C}$ activator isolated from Wikstroemia indica C.A. Mey. Biochem J 295: 321-327, 1993.

8. Hu K, Kobayashi H, Dong A, Iwasaki S and Yao X: Antifungal, antimitotic and anti-HIV-1 agents from the roots of Wikstroemia indica. Planta Med 66: 564-567, 2000.

9. Hall IH, Tagahara K and Lee KH: Antitumor agents LIII: The effects of daphnoretin on nucleic acid and protein synthesis of Ehrlich ascites tumor cells. J Pharm Sci 71: 741-744, 1982.

10. Wang JP, Raung SL, Kuo YH and Teng CM: Daphnoretin-induced respiratory burst in rat neutrophils is, probably, mainly through protein kinase C activation. Eur J Pharmacol 288: 341-348, 1995.

11. Chen HC, Chou CK, Kuo YH and Yeh SF: Identification of a protein kinase $\mathrm{C}(\mathrm{PKC})$ activator, daphnoretin, that suppresses hepatitis B virus gene expression in human hepatoma cells. Biochem Pharmacol 52: 1025-1032, 1996.

12. Ho WS, Xue JY, Sun SS, Ooi VE and Li YL: Antiviral activity of daphnoretin isolated from Wikstroemia indica. Phytother Res 24: 657-661, 2010.

13. Lee KH, Tagahara K, Suzuki H, et al: Antitumor agents. 49 tricin, kaempferol-3-O-beta-D-glucopyranoside and (+)-nortrachelogenin, antileukemic principles from Wikstroemia indica. J Nat Prod 44: 530-535, 1981.

14. Gu S and He J: Daphnoretin induces cell cycle arrest and apoptosis in human osteosarcoma (HOS) cells. Molecules 17: 598-612, 2012.

15. Yang ZY, Kan JT, Cheng ZY, et al: Daphnoretin-induced apoptosis in HeLa cells: a possible mitochondria-dependent pathway. Cytotechnology 66: 51-61, 2014.

16. Chen CC, Lin YC, Chen YP and Hsu HYJ: A study on the constituents of Wikstroemia indica C.A. Mey. Taiwan Pharm Assoc 33: 28-29, 1981.

17. Majumder PL and Sengupta GCJ: Chemical Investigation of Daphne cannabina Wall. J. Indian Chem Soc 45: 1058-1062, 1968.

18. Xiao R, Ferry AL and Dupont-Versteegden EE: Cell death-resistance of differentiated myotubes is associated with enhanced anti-apoptotic mechanisms compared to myoblasts. Apoptosis 16: 221-234, 2011.

19. Hanahan D and Weinberg RA: Hallmarks of cancer: the next generation. Cell 144: 646-674, 2011.

20. Jendrossek V: The intrinsic apoptosis pathways as a target in anticancer therapy. Curr Pharm Biotechnol 13: 1426-1438, 2012.

21. Ott M, Norberg E, Zhivotovsky B and Orrenius S: Mitochondrial targeting of $\mathrm{tBid} / \mathrm{Bax}$ : a role for the TOM complex? Cell Death Differ 16: 1075-1082, 2009.

22. Robertson JD and Orrenius S: Molecular mechanisms of apoptosis induced by cytotoxic chemicals. Crit Rev Toxicol 30: 609-627, 2000

23. Tamm I, Schriever F and Dörken B: Apoptosis: implications of basic research for clinical oncology. Lancet Oncol 2: 33-42, 2001.

24. Li SG, Wang YY, Ye ZY, et al: Proliferative and apoptotic effects of andrographolide on the BGC-823 human gastric cancer cell line. Chin Med J (Engl) 126: 3739-3744, 2013.

25. Yu J, Zhou X, He X, Dai M and Zhang Q: Curcumin induces apoptosis involving bax/bcl-2 in human hepatoma SMMC-7721 cells. Asian Pac J Cancer Prev 12: 1925-1929, 2011. 